\title{
Studies on the Preparation, Standardization and Preservation of Lepromin
}

\section{Comparative tests with the Dharmendra antigen containing lipid fraction of leprous nodule}

\author{
MAsahide ABE and Hikoji HijloKA \\ (National Institute for Leprosy Research) \\ Noboru TACHIKAWA and Kazuko OKAMURA \\ (Tama Zenshoen) \\ SHIGENORI ISHIHARA \\ (Suruga Leprosarium) \\ and SHIGENoBU KOBAYASHI \\ (Kuryu Rakusenen)
}

Having been found that the Dharmendra antigen combined with certain lipid fraction of leprous nodule (the "combined" antigen) gives stronger cutaneous reactions than the regular antigen in guinea pigs sensitized with leprosy bacilli, comparative tests between the above antigens as well as with a standard lepromin were done in leprosy patients, in order to find whether the effect of lipid fraction is seen in Fernandez reactions and/or Mitsuda reactions. The combined antigen was prepared by adding dried residue of the alcohol-insoluble lipid fraction to the Dharmendra antigen so that a weight-ratio of lipid to bacilli is $1: 4$, considering the yields of them from the same pool of leproma.

The results of comparative tests between the combined antigen and the Dharmendra demonstrated that the former gives more strong Fernandez reactions than the latter in 85 cases of non-lepromatous type, since a mean of differences in reactionsizes to the both antigens is statistically significant; while that in 406 cases of lepromatous type is not. With respect to the Mitsuda reactions, however, these antigens showed no difference in reaction-size of lepromatous as well as non-lepromatous cases.

Comparing with the standard lepromin, the combined antigen gave somewhat strong Fernandez reactions in 21 cases of non-lepromatous type. On the contrary, the combined antigen gave weaker Mitsuda reactions than the standard lepromin in 98 cases of lepromatous type.

These results indicated that the alcohol-insoluble lipid of leproma has an intensifying effect only to the Fernandez reactions in non-lepromatous cases. In spite of this fact, usefulness of Mitsuda or late reactions to the Dharmendra or combined antigen was discussed, s $\$$ far as observations in leprosy patients, according to a criterium of positive reactions $d / /$ fferent from that used for a lepromin. 


\title{
レプロミンの製法，力価試験並びに保存に関する研究
}

\author{
第 5 報 結節脂質添加 Dharmendra 抗原による比較試験
}

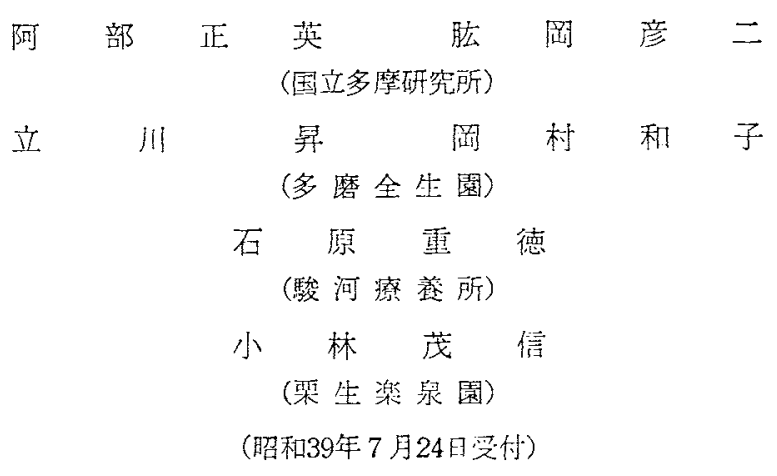

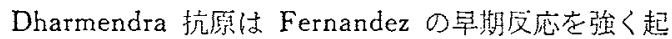

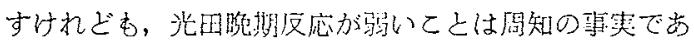
り，その理由はクロロホルム・エーテル処理により菌の 抗原性が修飾されるためと考えられている。Wade 結節のクロロホルム抽湤にアセトンを加えて，菌とと あにアセトン不溶脂䓄在沈測させ，ての脂劦を含んだ菌 浮遊液を抗原として，光时抁原と此较試験2)を行なっ た。その結果，乙の抗原化よる㤑期反応は，光田抗原に くらべると，な和らかに弱かったとのへている。

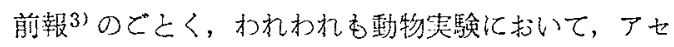
トン不溶脂斦源加により，Dharmendra 抗原の旦期反忘 が增強されることを明らかにしたが，との脂幦をさらに アルコールで分画すると, 増強作用はアルコール不溶分 画にのみ㫕出さ机，アルコール坷溶分画の添加は反応を むしろ弱くするととがわかった。そとで，前者の脂到の み老加えた Dharmendra 抗原を作り，楞準の Dharmendra および光田抗原との此较試験を多数の㝝患者につ いて試みた。

\section{材料およぴ方法}

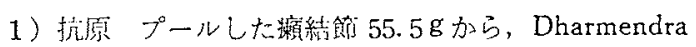
の方法4亿㮸い笨菌し, 乾燥菌体 $227 \mathrm{mg}$ を得た。これ 上り Dharmendra 抗原 (Dh) Lot 19を作製した。クロ ロホルム集菌の際抽出された結節脂宣のエーテル溶液を

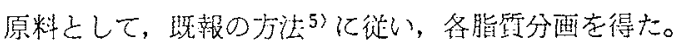
それらの収量は表1に示すごとくであった。菌とアルコ 一ル不溶脂繴との収量の比は約 4:1であったので，こ の制合に脂集を金む Dharmendra 抗原 $(\mathrm{Dh}+\mathrm{L})$ を作 彆した。すなわち、アルコール不溶脂質の必要量を含む クロロホルム浴液を乳鉥により，堅温に放踶してクロロ ホルムを蒸發させたの䒓，Dh在滴下しながら乳棒でよ く混和した。脂䓄は食璋水门に容舅にコロイド状に分散 し，粗い堄は告じなかった。出来上った Dh+Lは 0.5 $\%$ 不炭酸加食塩水 $1 \mathrm{cc}$ 中に $0.1 \mathrm{mg}$ の癭菌と $0.025 \mathrm{mg}$ のアルコール不溶脂毁を含む。なお，比較に用いた光田 抗原 (M) は别の結節プールから作裴した標準レプロミ ン Lot 19である。

Table 1. Yields of leprosy bacilli and lipid fractions from a pool of autoclaved leprosy nodules.

\begin{tabular}{l|r|r|r}
\hline \multicolumn{1}{c|}{ Materials } & Total amount & $\begin{array}{c}\text { Yield } \\
(\%)\end{array}$ & $\begin{array}{c}\text { Ratio of } \\
\text { bacilli : lipid }\end{array}$ \\
\hline Original leprosy nodule & $55.5 \mathrm{~g}$ & 100 & \\
Leprosy bacilli & $227 \mathrm{mg}$ & 0.41 & \\
Acetone soluble lipid & $1,660 \mathrm{mg}$ & 3.01 & $1: 7.3$ \\
Alcohol soluble lipib & $193 \mathrm{mg}$ & 0.35 & $1: 0.85$ \\
Alcohol insoluble lipid & $62 \mathrm{mg}$ & 0.11 & $1: 0.27$ \\
\hline
\end{tabular}


2）皮内反応 $\mathrm{Dh}+\mathrm{L} \varepsilon \mathrm{Dh}$ との比較試験には，呇生

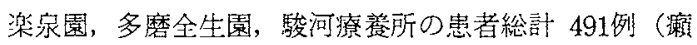
腫型 406例，非瀨腫型85例）を選えで行なった。また，

$\mathrm{Dh}+\mathrm{L}$ と $\mathrm{M}$ との此較は栗生楽泉園において，合計 119 例（濑腫型98例，非濑腫型21例）の患者について行なっ た。患者の左右前膊汇各抗原常法通り注射し，早期な らびに晚期反応の大きさを訪測した。抗原の注射部位差 をなくすため代，各患者群とあ，その約半数ずつで左右 亿注射する抗原を交換したが，駿河療養所の患者のみは 右側にDhを，左側に Dh+Lを注射した。

\section{成績}

通常の Dharmendra 抗原 (Dh) と結節脂質添加抗原 $(\mathrm{Dh}+\mathrm{L})$ とによる早期反応の大きさの相関を，瀨腫 (L) 型406例, 非瀨腫 (non-L) 型85例化つてしらべ た結果を表 2 扣よび表 3 に示す。L型では大多数の例が 斜線の上またはその近く注りり，雨抗原の力洒化差はな
いように思われる。しかし，non-L型では斜線より下方 汇多くの例があり，Dh+L の方が反応が強いととが明 らかである。

次に，標集光田抗原 $(\mathrm{M})$ と $\mathrm{Dh}+\mathrm{L}$ とによる晚期反 灾の相関を， L型98到，non-L型21例についてしらべた 結果を表 4 抢よび表 5 亿示す。し型においては，斜線よ り上方洺くの例があり，Mに比して Dh+L の晚期反 応が弱いととがわかる。他方，non-L型の場合には，检 查例数が少いために，明らかな差は見られなかった。

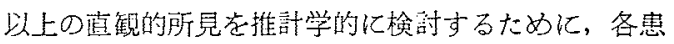
者について，2つの反応の大きさの差をしらべ，を机ら の分布於よで平均値から，乙の平均值が 0でないとみな しうるか，換言すれば，2つの抗原の力佂に差があると いいうるか否かをしらべた。その絬啉を表 6 亿示す。な お，相関表は省略したが，Dh+LとDhと飞よる晚期反 応および $\mathrm{M} と \mathrm{Dh}+\mathrm{L}$ とによる早期反応についても，同 様に反応の大きさの差を検討した（表 6 ）。差の平均値

Table 2. Correlation between the size of early reactions to the Dharmendra antigen (Dh) and that to the combined antigen $(\mathrm{Dh}+\mathrm{L})$ in 406 cases of lepromatous type.

\begin{tabular}{|c|c|c|c|c|c|c|c|c|c|c|c|c|c|c|c|c|c|c|}
\hline & & \multicolumn{16}{|c|}{ Size of reaction to $\mathrm{Dh}$ antigen $(\mathrm{mm})$} & \multirow[b]{2}{*}{ Total } \\
\hline & & 0 & 2 & 4 & 6 & 8 & 10 & 12 & 14 & 16 & 18 & 20 & 22 & 24 & 26 & 28 & 30 & \\
\hline & 0 & 22 & & 40 & 6 & 2 & & & & 1 & & & & & & & & 71 \\
\hline & 2 & & & 3 & 2 & & & & & & & & & & & & & 5 \\
\hline & 4 & 3 & & 119 & 27 & 5 & & & & & & & & & & & & 154 \\
\hline & 6 & 2 & 1 & 18 & 40 & 11 & 4 & & & & 1 & & & & 1 & & & 78 \\
\hline$\underline{\mathrm{E}}$ & 8 & 1 & & 6 & 5 & 11 & 11 & 1 & 1 & & & & & & & & & 36 \\
\hline+ & 10 & & & & 3 & 4 & 3 & 1 & 1 & & & & & & & & & 12 \\
\hline $\overrightarrow{\vec{\theta}}$ & 12 & 1 & & & 2 & & 2 & 2 & 1 & & 1 & & & & & & & 9 \\
\hline$\stackrel{8}{2}$ & 14 & & & 1 & 1 & 1 & & 1 & 4 & 1 & & & & & & & & 9 \\
\hline$\stackrel{\Xi}{\stackrel{g}{0}}$ & 16 & & & & 1 & & & & 2 & 2 & & & & 1 & & & & 6 \\
\hline$\stackrel{0}{\mathscr{B}}$ & 18 & & & & & & & & 1 & 2 & 1. & 2 & & & & & & 6 \\
\hline $\begin{array}{l}\overrightarrow{0} \\
0\end{array}$ & 20 & & & 1 & & & 1 & & & & 1 & & 1 & & & & & 4 \\
\hline$\vec{n}$ & 22 & & & & & & & 1 & 1 & 1 & & & & & & & & 3 \\
\hline & 24 & & & & & & & & & & & 1 & 1 & & & & 1 & 4 \\
\hline & 26 & & & & & & & & & & & 1 & & & & & 1 & 2 \\
\hline & 28 & & & & & & & & & & & & & & & & 1 & 1 \\
\hline & 30 & & & & & & & & & & & & & 1 & & 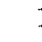 & 4 & 6 \\
\hline To & & 29 & 1 & 188 & 87 & 34 & 21 & 6 & 11 & 7 & 4 & 4 & 2 & 2 & 2 & 1 & 7 & 406 \\
\hline
\end{tabular}




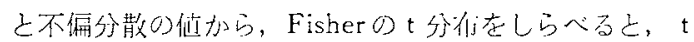

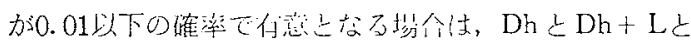

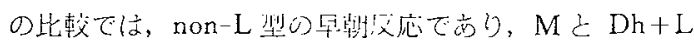

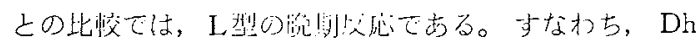

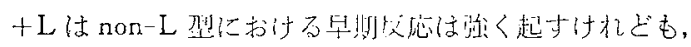

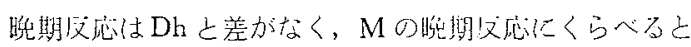

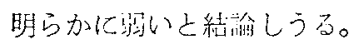

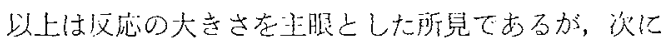

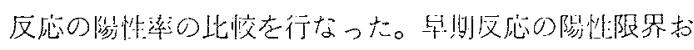

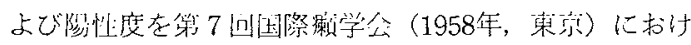

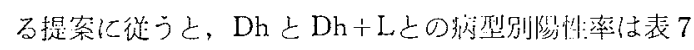
のでとくになる。L型の罚个には Dhと Dh+Lとの防

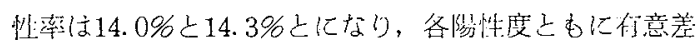
は見られない。他方，non-L 旺の鼎含には，降性率は

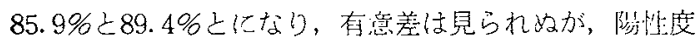

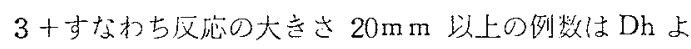

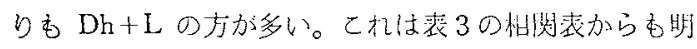

らかており, DhとDh+Lとの文応の大きさの差の分

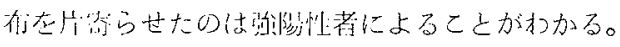

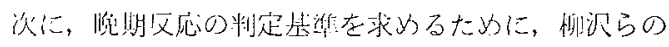

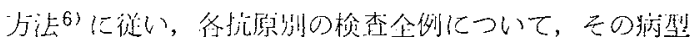

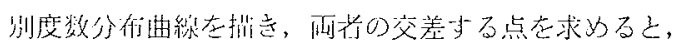

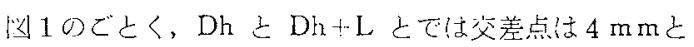

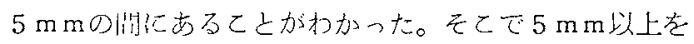

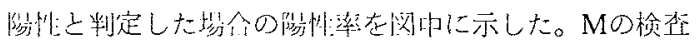
例数は少いので，Mのみを枪查した例数を归えて度数分

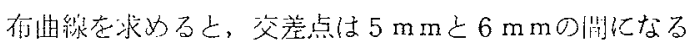

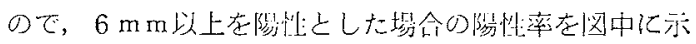

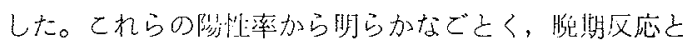

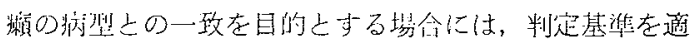
当に翌えれば，Dh あるいは Dh+Lによる悗期及感で

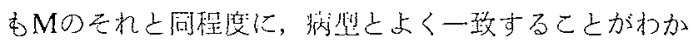
った。

Table 3. Correlation between the size of early reactions to the Dharmendra antigen $(\mathrm{Dh})$ and that to the combined antigen $(\mathrm{Dh}+\mathrm{L})$ in 88 cases of non-lepromatous type.

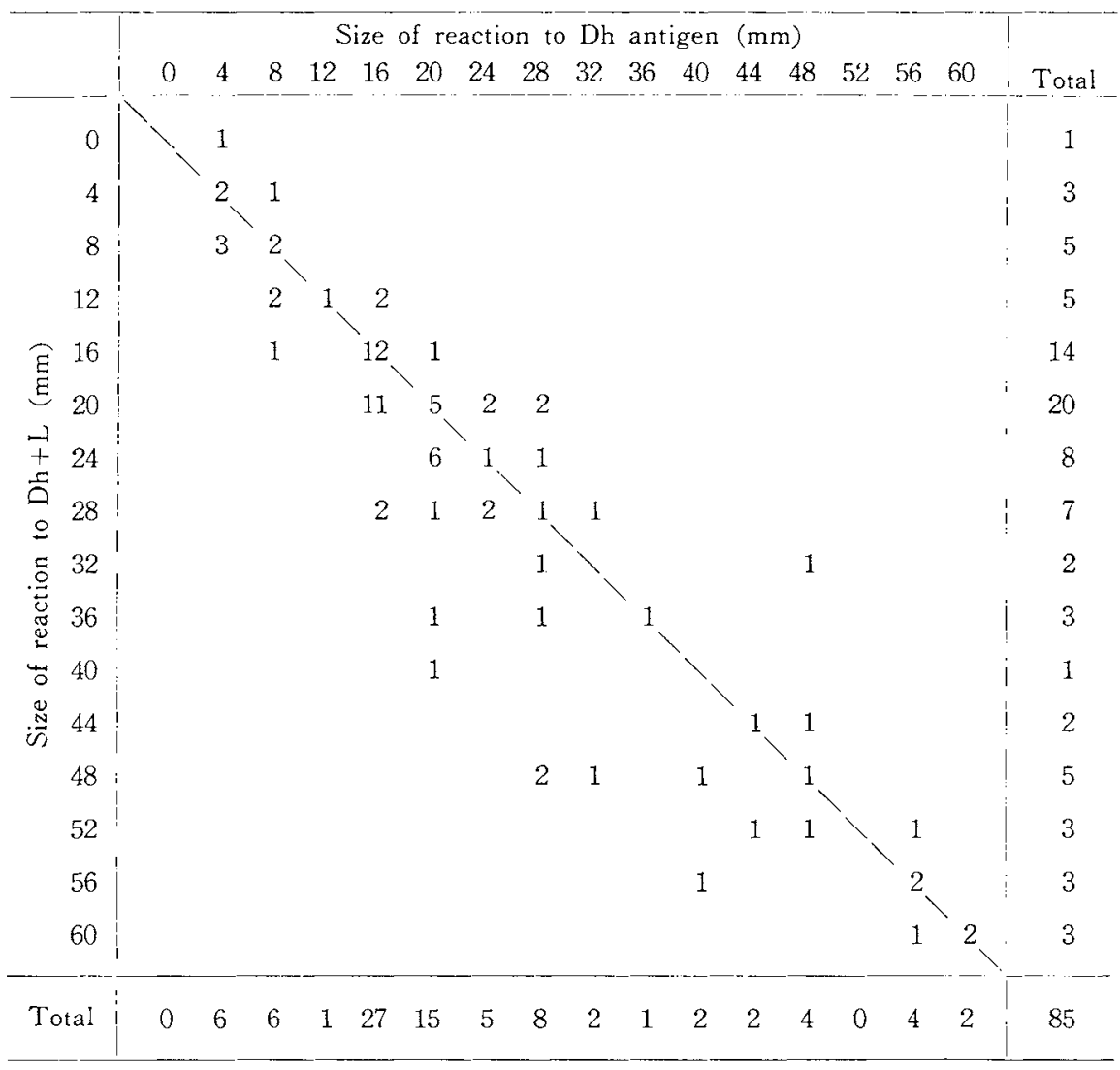




\section{考察}

この研㠰の最初の目的は, 結節脂臬のアルコール不溶 分画の添加に上り，Dharmendra 抗原の晩期 反応を堌 強させることにあったが，比较試験の結果は否定的であ

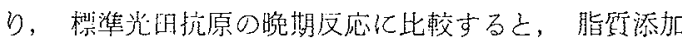
Dharmendra 抗原の反応は明らかに栨心ととが磪認され た。この絬果は Wade ら2゙の報告と一致している。彼 らの用いた “Purified bacillus suspension”(PBS) は 早期区応においても光田抗原より妈加ったと報告されて いるが，われわれの脂留添扣 Dharmendra 抗原はふつ うの抗原よりま， non-L㤠における早期反応を㤝く起す

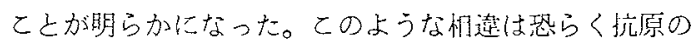

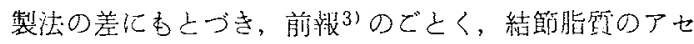

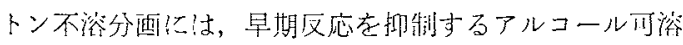
脂所が念まれるので，これを除いたアルコール不溶脂新 のみを加えたわれわれの抗原の方が早期反応の増強を著
明に呈したのであるう。しかしまた，此較試験の方法の 相違专若え极ばならぬ。Wade らは炎田抗原之PBS上 の早期反応陽性棌のみを比較しているが，われわれは，

Dharmendra 拈よび炎田抗原との比較を行なった。早期 反応陽性率に関しては，乙れらの抗原亡脂啠添加抗原上 は有意差を示さぬが，反応の大きさ $20 \mathrm{~mm}$ 以上の強院 性例に沶いては，脂貿添加抗原の力が明らかに大きな反 応を呈した。L型の埼合にはこのような効果は見られな

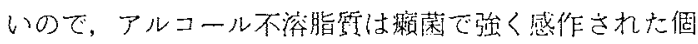
体に㧍けるアレルギー反応を特異的に增強させるといい う。

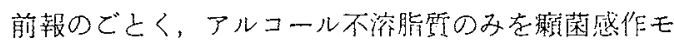
ルモットに注射しても，皮内反心は起ら驼，この脂 翼分画中に菌体ないしその破片が，Seitz 沪過板を通り 抜けて，混在した結果とは考え蜼い。むしる，結節中に は癩菌の代塮座物ないし崩壊物所が含まれ，それらがレ

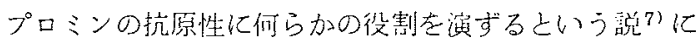

Table 4. Correlation between the size of late reactions to the Mitsuda antigen and that to the combined antigen ( $\mathrm{Dh}+\mathrm{L})$ in 98 cases of lepromatous type.

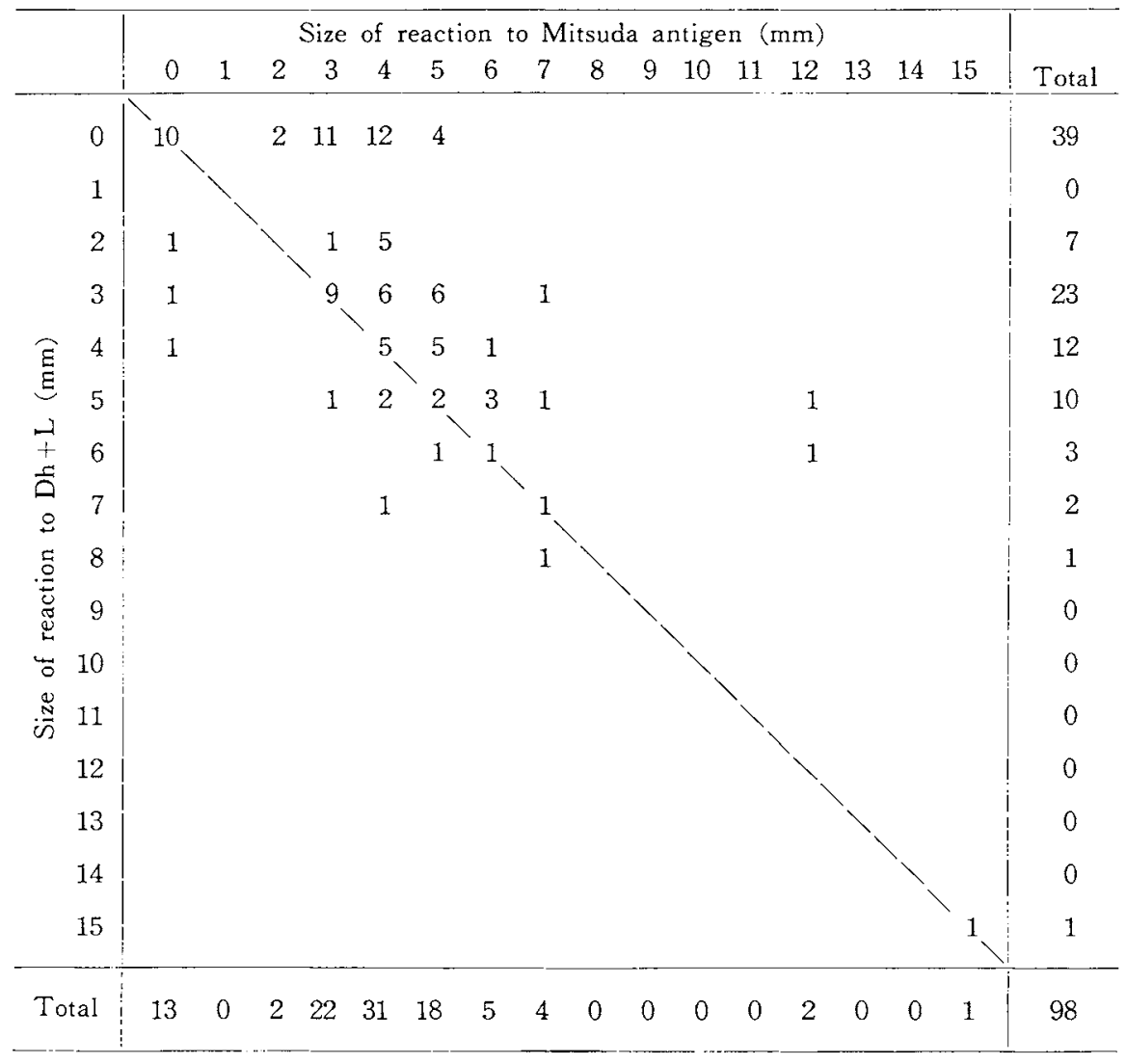


従い，このような物質の一部がアルコール不溶分画中に 含まれると解䣋したい。しかし，宿主側の組織に由来す る物質も当然考え枚ばなら好ので，上述のごとき早期反 店増強物賽の本態はアルコール不溶脂筫の化学尔析の絬 果に期待したい。

なお，Wade7)は癩結節中の菌化由来する上記のごと き物斦の存在を理由にして，レプロミンから組織成分を 除くべきでないと主張しているが，前述のでとく，われ われの用いた脂質分画は少く之も晚期反応には影響がな いように思われる。むしろ、レプロミン中の組織成分の

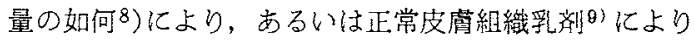
示さ机るごとき非特買的反応が晚期反応の大きさにかな り影響を拉よばすと考えられる。従って，紐穖成分を含 ま好しし今さとしても光田抗原にくらべればはるかに 少い) Dharmendra 抗原に上る晚期反灾の判定基準は光 田抗原の場合上当然異ってよいはずである。事害，柳沢 ら6?の方法化從い, 病型別度数分布曲線の交差する点か
ら陽性限界を求めると，図 1 のごとく，Dharmendra 抗 原および脂質添加抗原では， $5 \mathrm{~mm}$ 以上を淂性としてよ いととがわかった。とれは第8 回国際癞学会（1963年， ブラジル）において提案された判定規準と一致してい る。この基準仪從うと, Dharmendra 抗原あるいはそれ に脂質分画を加えた抗原です，陽性率の病型之の一致は かなりよい。それに此して，光田抗原の場合には，上記 の国際募準に從う之，L型の37.8\%が陽性となるので， 病型との一政をよくするためには，分布曲線の交差点加 ら考えて $6 \mathrm{~mm}$ 以上を榢性とすべきであるう。とのよう に，レプロミン反応を獭患者の病型あるいは予後の判定 に役立てる場合には，反忘の判定基準索適当に設讨れ ば，Dharmendra 抗原による晚期反灾でも十分に役立つ ように思われる。

しかしレプロミン反応を近年一層重要性を增してき た疫学的調查研究に用いる場合，特们幼小児のレプロミ ン反応の観察においては，光田抗原と Dharmendra抗原

Table 5. Corelation between the size of late reactions to the Mitsuda antigen and that to the combined antigen $(\mathrm{Dh}+\mathrm{L})$ in 21 cases of non-lepromatous type.

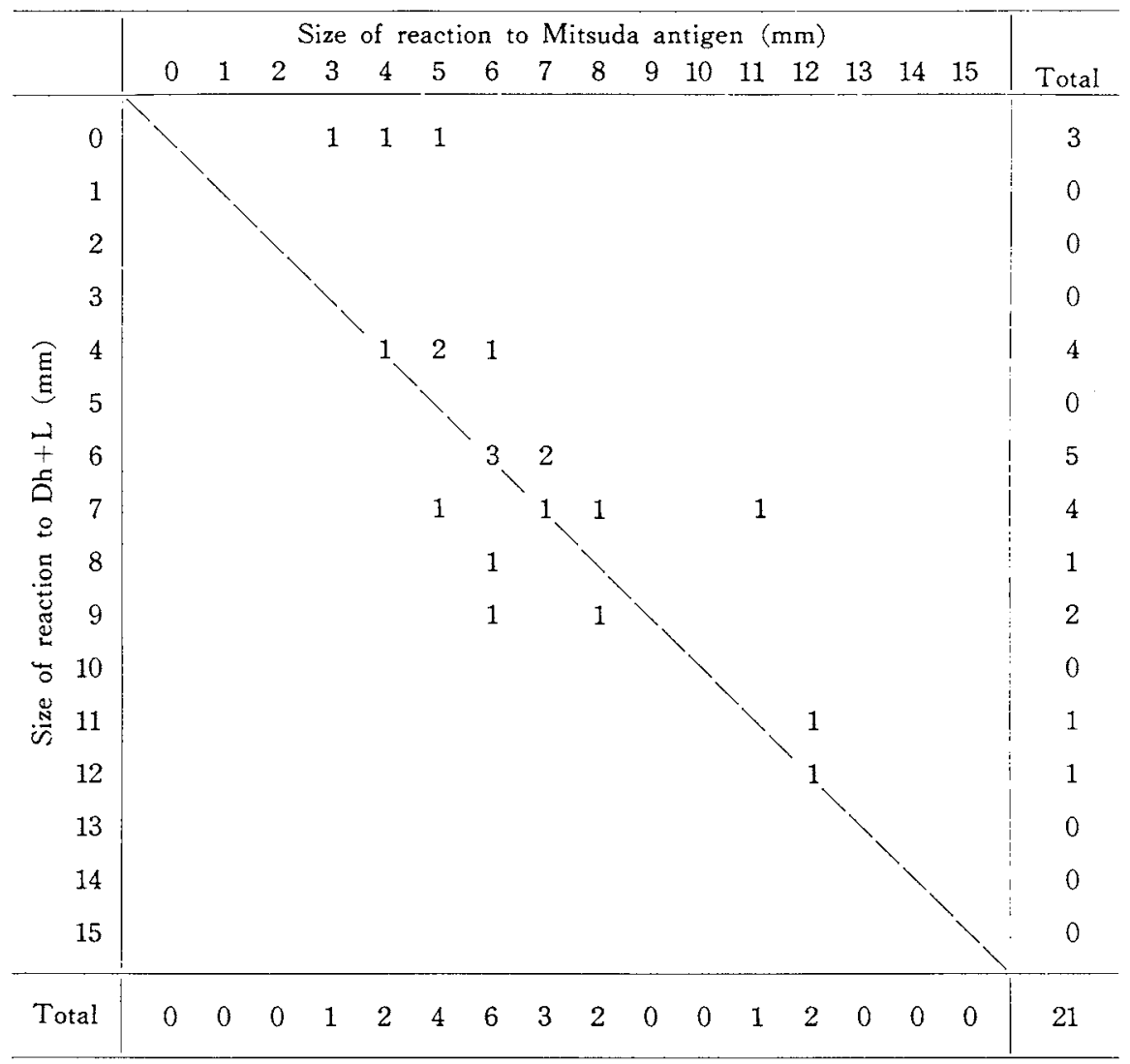


Table 6. Distribution of difference in size of reactions to Dharmendra (Dh) or Mitsuda (M) antigens and that to the combined antigen $(\mathrm{Dh}+\mathrm{L})$.

\begin{tabular}{|c|c|c|c|c|c|c|c|c|c|c|c|}
\hline \multirow{3}{*}{\multicolumn{4}{|c|}{$\begin{array}{l}\text { Antigens compared } \\
\text { Phase of reaction } \\
\text { Type of disease }\end{array}$}} & \multicolumn{4}{|c|}{$(\mathrm{Dh})-(\mathrm{Dh}+\mathrm{L})$} & \multicolumn{4}{|c|}{$(\mathrm{M})-(\mathrm{Dh}+\mathrm{L})$} \\
\hline & & & & \multicolumn{2}{|c|}{ Early } & \multicolumn{2}{|c|}{ Late } & \multicolumn{2}{|c|}{ Early } & \multicolumn{2}{|c|}{ Late } \\
\hline & & & & $\mathrm{L}$ & Non-L & $\mathrm{L}$ & Non-L & L & Non-L & $\mathrm{L}$ & Non-L \\
\hline \multirow{13}{*}{ 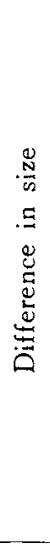 } & \multirow{13}{*}{ 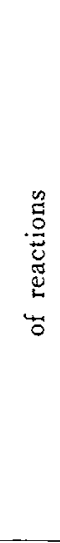 } & \multirow{13}{*}{ है } & $11-$ & 3 & 2 & 0 & 0 & 1 & 2 & 0 & 0 \\
\hline & & & $9-10$ & 1 & 1 & 0 & 0 & 0 & 0 & 0 & 0 \\
\hline & & & $7-8$ & 4 & 1 & 0 & 1 & 1 & 0 & 1 & 0 \\
\hline & & & $5-6$ & 10 & 0 & 2 & 0 & 5 & 0 & 5 & 1 \\
\hline & & & $3-4$ & 63 & 9 & 55 & 6 & 12 & 2 & 24 & 3 \\
\hline & & & $1-2$ & 83 & 12 & 66 & 15 & 31 & 2 & 30 & 7 \\
\hline & & & 0 & 154 & 6 & 182 & 24 & 17 & 1 & 28 & 5 \\
\hline & & & $-1--2$ & 45 & 22 & 56 & 32 & 20 & 3 & 7 & 4 \\
\hline & & & $-3^{-}-4$ & 23 & 11 & 33 & 6 & 2 & 1 & 3 & 1 \\
\hline & & & $-5^{-}-6$ & 7 & 7 & 9 & 0 & 7 & 1 & 0 & 0 \\
\hline & & & $-7--8$ & 7 & 4 & 1 & 0 & 1 & 2 & 0 & 0 \\
\hline & & & $-9--10$ & 4 & 1 & 0 & 1 & 0 & 2 & 0 & 0 \\
\hline & & & $-11-$ & 2 & 9 & 0 & 0 & 1 & 5 & 0 & 0 \\
\hline \multicolumn{4}{|c|}{ Total } & 406 & 85 & 404 & 85 & 98 & 21 & 98 & 21 \\
\hline \multirow{2}{*}{\multicolumn{4}{|c|}{$\begin{array}{l}\text { Mean of difference } \\
\text { Unbiased variance }\end{array}$}} & 0.384 & -2.42 & 0.072 & -0.26 & 0.408 & -3.91 & 1.47 & 0.714 \\
\hline & & & & 3.1 & 6.4 & 1.98 & 2.13 & 3.64 & 9.9 & 2.04 & 2.05 \\
\hline \multirow{2}{*}{\multicolumn{4}{|c|}{ Probability }} & 2. 18 & 3.39 & 0.73 & 1.12 & 1. 13 & 1.81 & 7.14 & 1.59 \\
\hline & & & & $0.02-0.05$ & $5<0.01$ & $.4-0.5$ & $0.2-0.3$ & $2-0.3$ & $0.05^{-0.1}$ & $<0.001$ & $0.1-0.2$ \\
\hline
\end{tabular}

Table 7. Comparison of positive percentage in early reactions to the Dharmendra antigen (Dh) and those to the combined antigen $(\mathrm{Dh}+\mathrm{L})$.

\begin{tabular}{|c|c|c|c|c|c|c|c|c|c|c|}
\hline \multirow{3}{*}{\multicolumn{2}{|c|}{ Grade }} & \multirow{3}{*}{$\begin{array}{l}\text { Size } \\
(\mathrm{mm})\end{array}$} & \multirow{2}{*}{\multicolumn{4}{|c|}{$\begin{array}{cc}\text { Lepromatous } & (406) \\
\mathrm{Dh} & \mathrm{Dh}+\mathrm{L}\end{array}$}} & \multicolumn{4}{|c|}{ Non-lepromatous (85) } \\
\hline & & & & & & & \multicolumn{2}{|c|}{$\mathrm{Dh}$} & \multicolumn{2}{|c|}{$\mathrm{Dh}+\mathrm{L}$} \\
\hline & & & No. & $\%$ & No. & $\%$ & No. & $\%$ & No. & $\%$ \\
\hline Negative & $(-)$ & $0-4$ & 218 & 53.7 & 230 & 56.9 & 6 & 7.1 & 4 & 4. 7 \\
\hline Doubtful & $( \pm)$ & $5-9$ & 131 & 32.3 & 118 & 29.1 & 6 & 7.1 & 5 & 5.9 \\
\hline \multirow[t]{3}{*}{ Positive } & $(1+)$ & $10-14$ & 28 & 6.9 & 26 & 6.4 & 11 & 12.9 & 9 & 10.6 \\
\hline & $(2+)$ & $15-19$ & 13 & 3. 2 & 13 & 3.2 & 28 & 33.0 & 26 & 30.6 \\
\hline & $(3+)$ & 20 or more & 16 & 3.9 & 19 & 4. 7 & 34 & 40.0 & 41 & 48.2 \\
\hline
\end{tabular}

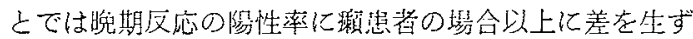
ることが知られており2，その理由として，派存のアレ ルギーのない佪体では，光团挄原が“Microvaccination” の效果を有するのに対して，Dharmendra 抗原にはそれ がそしいことが主張されているク。われわれは従来，瀬 喼者汇おける比較試験を主とし，またそれに限定せざる

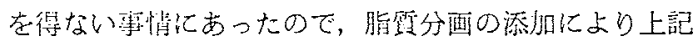

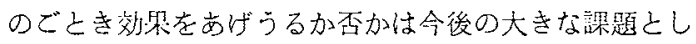
たい。しかしそれには, 光田抗原の非特巽的反応を避け
るために，菌の抗原赀を変えずに組織成分のみを除去し た精製菌浮遊腹の作製ならびにをれを祭準とした比較試 験が必要であろう。

\section{総括}

結節脂澌のアルコール不溶分画を菌体の 4 尔の 1 量加 えた Dharmendra 抗原を作り，敉準 Dharmendra 执よ び光田抗原との比較試験を賴患者について行なった。 脂頭添加Dharmendra 抗原による早期反応は，非瀨腫 


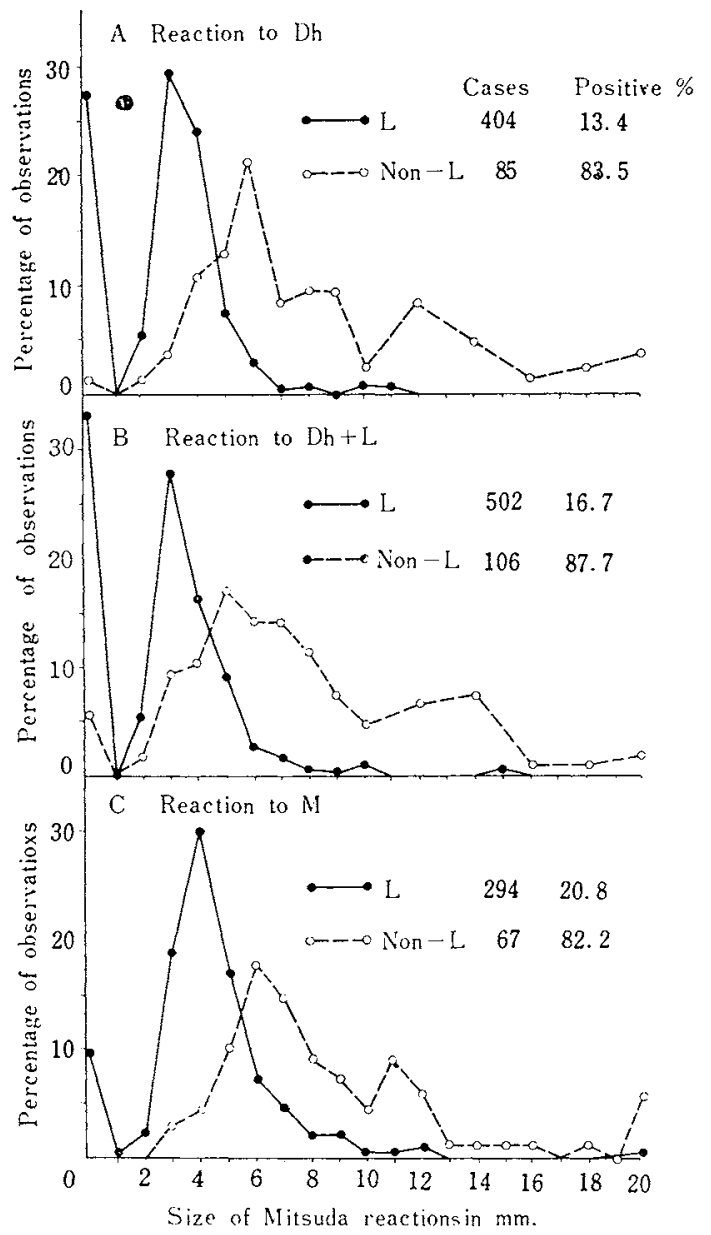

Fig. 1. Distribution curves, of lepromatous and non-lepromatous cases, by sizes of Mitsuda reactions to the following antigens: A. the Dharmendra antigen ( $\mathrm{Dh}), \mathrm{B}$. the Dharmendra antigen combined with alcohol-insoluble lipid $(\mathrm{Dh}+\mathrm{L})$, and $\mathrm{C}$. the standard lepromin (M). Numbers of cases tested and percentages of positive reactions are indicated in the figure, calculating from criteria that positive reactions to $\mathrm{Dh}$ and $\mathrm{Dh}+\mathrm{L}$ are considered to be $5 \mathrm{~mm}$ or more in size, while those to $M$ is $6 \mathrm{~mm}$ or more.

型85例に戈いては，通常のDharmendra挩原の反応上り 明らかに就ったが，䘽腫型 406例では大差なく，また

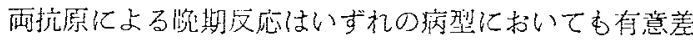
を示さなかった。

脂货添加 Dharmendra扮原を光田抗原と比較すると，

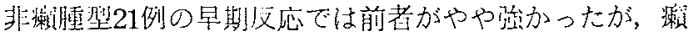

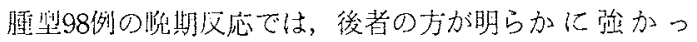
た。

以上の所罗から，結節脂筫のアルコール不溶分画に

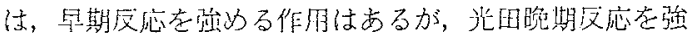
める作用はないことが明らかになった。しかし，濑患者 においては，Dharmendra 抗原による晛朋反応は，判定 基準を適当に選べば，光田抗展による場合上同㥞に，病 型判定に使肞することができると桨えられる。

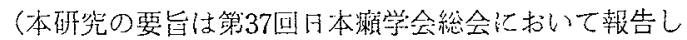

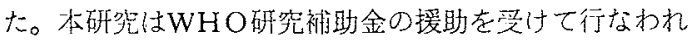
t)

\section{文献}

1) Wade, H.W. : Lepromin vs purified bacillus suspension. I. Preparation of a purified bacillus suspension (with a note of Nile-blue staining of smears). Internat. J. Leprosy 30, 19 (1962)

2) Wade, H. W. et al : Lepromin vs purified bacillus suspension. II. Comparative tests with a purified bacillus suspension. ibid 30, 27 (1962)

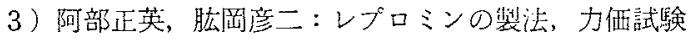
ならびに保存に関する研究(4)，脱脂獺菌感作モルモ ットによる力洒試験の甚憷的研究，レプラ，33，22 (1964)

4) Dharmendra : The lepromin test-a review. Leprosy Rev. 18, 92 (1947)

5) Abe, M. : Serological relationships of leprosy, tuberculosis and syphilis. II. In vitro antigenicity of the lipid recovered from leprous nodule. La Lepro 26 28 (Selected Article), 59 (1960)

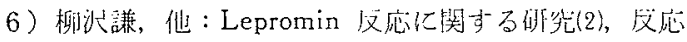
の判定齿染，レプラ，24，328(1955)

7 ) Wade, H. W. : Lepromin : Standardization and technique. Working document presented at the Expert Committee on Leprosy, WHO, Geneva, Switzerland (1959)

8）阿部边英他：レプロミンの製法，力伍陚験ならびに

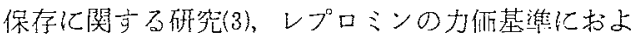
ぼす組織成分の影墕，レプラ，32，133（1963）

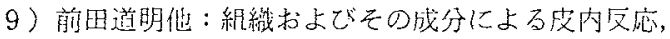
レプラ, 33, 7 (1964) 